\title{
Serum BDNF Levels are Not Associated with the Antidepressant Effects of Nonconvulsive Electrotherapy
}

This article was published in the following Dove Press journal: Neuropsychiatric Disease and Treatment

\author{
Wei Zheng' \\ Miao-Ling Jiang' \\ Hong-Bo $\mathrm{He}^{\prime}$ \\ Ri-Peng Li' \\ Qi-Long $\mathrm{Li}^{\prime}$ \\ Chun-Ping Zhang' \\ Su-Miao Zhou' \\ Su Yan' \\ Yu-Ping Ning ${ }^{1,2}$ \\ Xiong Huang' \\ 'The Affiliated Brain Hospital of \\ Guangzhou Medical University \\ (Guangzhou Huiai Hospital), Guangzhou, \\ People's Republic of China; ${ }^{2}$ The First \\ School of Clinical Medicine, Southern \\ Medical University, Guangzhou, \\ Guangdong, People's Republic of China
}

Correspondence: Xiong Huang; Yu-Ping Ning

The Affiliated Brain Hospital of Guangzhou Medical University (Guangzhou Huiai Hospital), 36 Mingxin Road, Liwan District, Guangzhou, People's Republic of China

Tel +86-189-22165303;

$+86-185-10808443$

Fax +86-20-8I778484; +86-20-8I89|425

Email I195768576@qq.com;

ningjeny@I26.com
Objective: Brain-derived neurotrophic factor (BDNF) has been implicated in the pathophysiology of depression and in the antidepressant response. This study examined whether changes in serum BDNF levels are associated with the antidepressant effects of nonconvulsive electrotherapy (NET).

Methods: For BDNF analyses, serum samples were collected from 20 patients with treatment-refractory depression (TRD) and from 20 healthy controls. Serum samples were also collected from patients following a course of NET.

Results: Although significantly lower baseline serum BDNF levels were observed in TRD patients than in healthy controls, no changes in serum BDNF levels were found in TRD patients after a course of NET compared to baseline. No significant association was found between serum BDNF levels and depression severity.

Conclusion: Serum BDNF levels appear to have no clinical utility in the prediction of the antidepressant effects of NET in patients with TRD. Future studies of higher quality and with larger sample sizes are needed to confirm these findings.

Keywords: brain-derived neurotrophic factor, nonconvulsive electrotherapy, treatmentrefractory depression

\section{Introduction}

Major depressive disorder (MDD), a major mental disorder, is the leading cause of disability around the world, accounting for approximately $4.4 \%$ of the world's population. ${ }^{1}$ Numerous studies have demonstrated that decreased expression of brain-derived neurotrophic factor (BDNF) in limbic structures induced by stress could contribute to depression. ${ }^{2-4}$ BDNF is a neurotrophin essential for neuronal development and survival, neuroprotection, synaptic plasticity, and cognition. ${ }^{5}$

In support of the neurotrophin hypothesis of depression, a growing number of studies have shown that stress decreases the expression of hippocampal BDNF levels in rodents, ${ }^{6}$ and both chronic electroconvulsive therapy (ECT) and antidepressants increase the enhanced induction and prolong the expression of brain BDNF levels ${ }^{7}$ and reverse or block the effects of stress on BDNF. ${ }^{2}$ Several studies have shown that BDNF levels are lower in the cerebrospinal fluid, ${ }^{8}$ plasma, ${ }^{9}$ serum, ${ }^{4,10}$ platelets, ${ }^{11}$ and brain $^{12}$ in patients with MDD than in healthy controls. Most of these studies, ${ }^{10,13,14}$ but not all of them, ${ }^{15}$ reported that decreased BDNF levels are reversed in those who responded to antidepressants compared with those who were remittent to antidepressants. 
ECT is the most reliably effective therapy, to date, in the treatment of patients with treatment-resistant depression (TRD). ${ }^{16-18}$ However, ECT is associated with adverse cognitive effects, resulting in some TRD patients refusing the use of ECT. ${ }^{19}$ Surprisingly, Regenold et al recruited 13 TRD patients who refused ECT and participated in an uncontrolled, open-label study adjunctive treatment study of nonconvulsive electrotherapy (NET) ${ }^{19}$ They found that the antidepressant effects of NET in treating TRD patients were similar to those of ECT, and adverse cognitive effects were not observed. ${ }^{19}$

Although there are high clinical responses and remission rates of NET in TRD, ${ }^{19}$ its neurobiological mechanism of action remains unclear. To date, only one study has examined plasma BDNF levels in patients with treatment-resistant unipolar and bipolar depression following a course of NET, finding that plasma BDNF levels of TRD patients increased insignificantly following a course of NET, and changes in plasma BDNF levels did not significantly correlate with changes in the severity of depressive symptoms. ${ }^{19}$ However, the association of the antidepressant effects of NET and the changes in serum BDNF levels was unclear.

The objectives of this study were to examine the association of serum BDNF levels and the antidepressant effects of NET in Chinese patients with TRD. We hypothesized that serum BDNF levels would be lower in TRD patients than in healthy controls and that serum BDNF levels would be associated with the therapeutic response to NET in TRD patients.

\section{Methods}

\section{Participant Selection}

This study of adjunctive NET for patients with TRD occurred at the Affiliated Brain Hospital of Guangzhou Medical University between January 2017 and December 2017 and was approved by the Affiliated Brain Hospital of Guangzhou Medical University's institutional review board. This study was conducted in accordance with the Declaration of Helsinki. All subjects signed written informed consent before participation.

Inclusion criteria of participants included: (1) inpatients aged 18 to 50 years old; (2) satisfied the Structured Clinical Interview for the Diagnostic and Statistical Manual of Mental Disorders, Fourth Edition (DSM-IV) diagnostic criteria ${ }^{20}$ for MDD with a current major depressive episode; (3) had a baseline score of $\geq 17$ on the 17-item Hamilton Depression Rating Scale (HAMD-17); ${ }^{21}$ and (4) with TRD, defined as a failure to respond to at least two classes of antidepressants at sufficient dosages for a full course of treatment. ${ }^{22}$

Patients were excluded if they met one of the following criteria: (1) met any other serious mental disorder of DSM-IV diagnostic criteria, including schizophrenia, bipolar disorder, organic mental disorders, or substance use disorder; (2) had any neurological illnesses or serious medical conditions; (3) were pregnant or breast feeding; (4) had a history of seizures; (5) had undergone ECT within the past 3 months; (6) had a foreign body such as intracranial electrode or pacemaker; or (7) had an inability to follow the study procedure.

Twenty healthy individuals, who were frequencymatched to patients with TRD by sex and age, were enrolled from the local community during the same period. Healthy controls with a history of serious physical diseases and alcohol or other substance abuse/dependence were excluded.

\section{Study Procedure}

All subjects underwent detailed pre-NET examinations, including physical and neurological examinations, electrocardiogram (ECG), electroencephalography (EEG), blood and urine tests, and chest X-ray. TRD patients received propofol $(1.0 \mathrm{mg} / \mathrm{kg})$ as intravenous anesthesia during NET. Succinylcholine $(1.0 \mathrm{mg} / \mathrm{kg})$ was intravenously administered as a muscle relaxant after the induction of anesthesia. Patients received six consecutive bilateral NET sessions three times per week using a Somatics Thymatron ${ }^{\circledR}$ IV device (Somatics LLC, Lake Bluff, Illinois, USA). All subjects continued to take psychotropic agents during NET.

The stimulus parameters of NET in this study included a pulse width of $0.5 \mathrm{~ms}$, a constant current of $0.9 \mathrm{~A}$, and a frequency of $20 \mathrm{~Hz}$. As recommended by Regenold et al's study, ${ }^{19}$ the stimulus intensity of NET in this study was set at $1 / 8$ of the standard ECT dose as estimated by the half-age method. The usual ECT protocol was also utilized to evaluate seizures or a lack of seizures by observing tonic-clonic movements and using EEG. Blood pressure, pulse frequency, and respiratory rate were recorded by trained clinicians before anesthesia and $10 \mathrm{~min}$ after the NET procedure.

\section{Measurement of Depressive Symptoms}

The HAMD- $17^{21}$ was used to evaluate depressive symptoms at baseline and after the first, third and sixth sessions of NET. Given that a large proportion of patients with severe depression showed a response to $\mathrm{ECT}^{23}$ antidepressant response was defined as $\geq 60 \%$ improvement from the baseline 
depression score as measured by the HAMD- $17^{23,24}$ rather than $\geq 50 \%$ improvement (ie, the traditional criterion). It has been widely used in previous studies. ${ }^{23-26}$ Mulder et al found that using a $50 \%$ reduction in HAMD scores leads to a marginally higher sensitivity $(96.1 \%)$ but a lower specificity $(71.4 \%)$ and the sometimes used $60 \%$ reduction is close to the optimal compromise $(87.4 \%$ sensitivity, $82.1 \%$ specificity). ${ }^{26}$

\section{Serum BDNF Levels}

For the depression cohort, blood samples were collected at baseline and at the end of the course of NET. For the healthy controls, a single blood sample was collected at baseline. All blood samples were collected between 7:00 and 9:00 am after an overnight fast. After collection, blood samples were stored at $-80{ }^{\circ} \mathrm{C}$ until assay. According to the manufacturer's directions and as described previously, ${ }^{27}$ serum BDNF levels were measured using an enzyme-linked immunosorbent assay (ELISA; sensitivity $=0.08 \mathrm{ng} / \mathrm{mL})(B D N F$ Emax Immunoassay System, Promega, USA). Serum BDNF levels were determined by absorbance at a wavelength of $450 \mathrm{~nm}$ using optical density values against standard curves.

\section{Statistical Analysis}

All statistical analyses were conducted using SPSS version 23.0 for Windows. The comparison between TRD patients and healthy controls with regard to demographics and clinical variables was conducted by the chi-squared test or Fisher's exact test for categorical variables and by Student's $t$-test or the Mann-Whitney $U$-test for continuous variables, as appropriate. Linear mixed model analysis was conducted to compare the changes in HAMD-17 scores and serum BDNF levels at each assessment time point between responders and responders (defined as a $\geq 60 \%$ improvement from the baseline depression score as measured by the HAMD17). Correlation analyses were conducted for relationships between HAMD-17 scores and serum BDNF levels in TRD patients. Statistical significance was set at $p<0.05$.

\section{Results}

\section{Participant Characteristics}

Table 1 summarizes the demographic and clinical characteristics of TRD patients and healthy controls participating in this study. Figure 1 shows that the serum BDNF levels in 20 TRD patient samples were lower than those in 20 healthy control samples $(p<0.001)$.
Table I Characteristics of TRD Patients and Healthy Controls

\begin{tabular}{|c|c|c|c|c|c|c|c|}
\hline \multirow[t]{2}{*}{ Variables } & \multicolumn{2}{|c|}{$\begin{array}{l}\text { TRD } \\
\text { Patients } \\
(n=20)\end{array}$} & \multicolumn{2}{|c|}{$\begin{array}{l}\text { Healthy } \\
\text { Controls } \\
(n=20)\end{array}$} & \multicolumn{3}{|c|}{ Statistics } \\
\hline & $\mathbf{N}$ & $\%$ & $\mathbf{N}$ & $\%$ & $\mathrm{X}^{2}$ & df & $p$ \\
\hline Male & 11 & 55.0 & 11 & 55.0 & 0.001 & 1 & 1.00 \\
\hline Married & 8 & 40.0 & & & & & \\
\hline \multirow[t]{2}{*}{ Responder } & 12 & 60.0 & & & & & \\
\hline & Mean & SD & Mean & SD & $\mathrm{T}$ & df & $p$ \\
\hline Age (years) & 29.2 & 8.7 & 31.0 & 8.1 & 0.8 & 38 & 0.50 \\
\hline $\begin{array}{l}\text { Baseline serum } \\
\text { BDNF level } \\
(\mathrm{ng} / \mathrm{mL})\end{array}$ & 5.2 & 2.9 & 24.2 & 5.9 & 13.8 & 38 & $<0.001$ \\
\hline $\begin{array}{l}\text { Post-NET serum } \\
\text { BDNF levels } \\
(\mathrm{ng} / \mathrm{mL})\end{array}$ & 5.3 & 2.8 & & & & & \\
\hline $\begin{array}{l}\text { Baseline HAMD- } \\
17 \text { scores }\end{array}$ & 26.2 & 2.4 & & & & & \\
\hline $\begin{array}{l}\text { Post-NET HAMD- } \\
17 \text { scores }\end{array}$ & 10.4 & 2.0 & & & & & \\
\hline
\end{tabular}

Note: Bolded values are $p<0.05$.

Abbreviations: BDNF, brain-derived neurotrophic factor; df, degrees of freedom; HAMD-17, 17-item Hamilton Depression Rating Scale; NET, nonconvulsive electrotherapy; SD, standard deviation; TRD, treatment-refractory depression.

\section{Serum BDNF Levels and Antidepressant Response}

In linear mixed models, serum BDNF levels over time showed no significant difference between responders and nonresponders, even among the total sample (all $p>0.05$ )

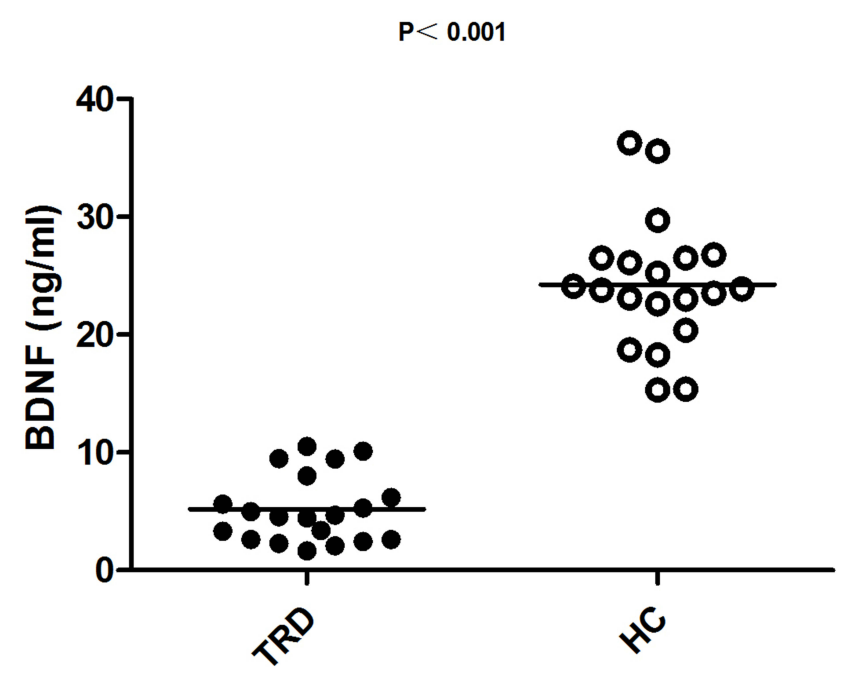

Figure I Baseline serum BDNF levels in TRD patients and healthy controls. 
(Table 2 and Figure 2). However, HAMD-17 scores showed significant main effects of group-by-time interactions $(\mathrm{F}=5.1$, $p=0.005)$ and time $(\mathrm{F}=308.0, p<0.001)$ (Table 2). The antidepressant response rates were $60 \%(12 / 20)$ after NET.

\section{Relationship Between Serum BDNF Levels and Depression Severity}

No significant correlations were found between baseline serum BDNF levels and changes in HAMD-17 scores at each assessment point (all $p>0.05$ ) or between changes in serum BDNF levels and changes in HAMD-17 scores at each assessment point (all $p>0.05$ ) (Supplemental Table 1).

\section{Discussion}

To the best of our knowledge, this is the first study to examine the association between serum BDNF levels and the antidepressant response to NET. Our findings indicate significantly lower serum BDNF levels in patients with TRD than in healthy controls at baseline. NET did not significantly alter serum BDNF levels in either responders or nonresponders, even among the total sample. Additionally, no notable association was found between serum BDNF levels and changes in depression severity following the course of NET.

Consistent with our findings, numerous case-control studies $^{28-30}$ and meta-analyses ${ }^{31,32}$ have consistently concluded that the serum BDNF levels of MDD patients were significantly lower than those of healthy controls. However, blood BDNF levels in MDD patients are quite varied when compared with those of healthy controls. ${ }^{28,33}$ For example, Bocchio-Chiavetto et al reported no significant difference in plasma BDNF levels between MDD patients and healthy controls, although they found significantly lower serum BDNF levels in patients with MDD than in healthy controls. ${ }^{28}$ In contrast, another study found that plasma

Table 2 Comparisons of Serum BDNF Levels and HAMD-17 Scores Between Responders and Nonresponders Using Linear Mixed Model Analysis

\begin{tabular}{|c|c|c|c|c|c|c|}
\hline \multirow[t]{2}{*}{ Variables } & \multicolumn{2}{|c|}{$\begin{array}{l}\text { Group-by- } \\
\text { Time } \\
\text { Interaction }\end{array}$} & \multicolumn{2}{|c|}{$\begin{array}{l}\text { Time Main } \\
\text { Effect }\end{array}$} & \multicolumn{2}{|c|}{$\begin{array}{l}\text { Group } \\
\text { Main } \\
\text { Effect }\end{array}$} \\
\hline & $\mathbf{F}$ & $p$ & $\mathbf{F}$ & $\mathbf{p}$ & $\mathbf{F}$ & $p$ \\
\hline HAMD-I7 scores & 5.1 & 0.005 & 308.0 & $<0.001$ & 1.7 & 0.20 \\
\hline Serum BDNF levels & 0.5 & 0.51 & 0.2 & 0.66 & 1.1 & 0.30 \\
\hline
\end{tabular}

Note: Bolded values are $p<0.05$.

Abbreviations: HAMD-17, 17-item Hamilton Depression Rating Scale, BDNF, brain-derived neurotrophic factor.

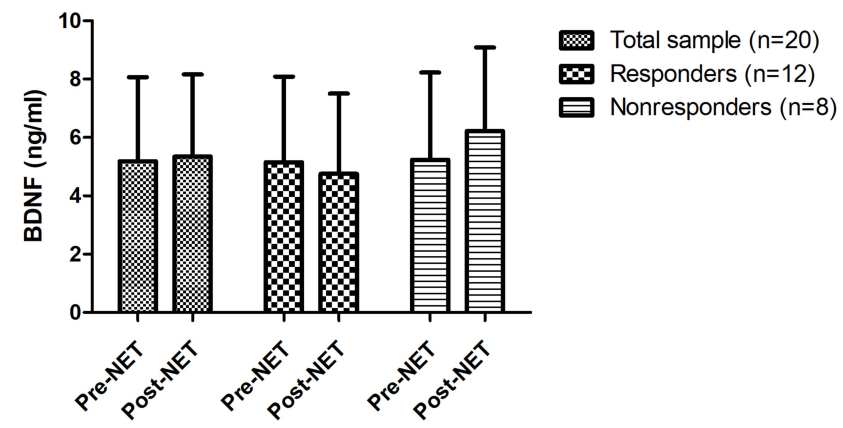

Figure 2 Change in serum BDNF levels following six NET sessions in patients with TRD.

BDNF levels were significantly lower in patients with MDD than in healthy controls. ${ }^{33}$

In this study, serum BDNF levels increased insignificantly from a baseline mean (standard deviation) of $5.2(2.9) \mathrm{ng} / \mathrm{mL}$ to $5.3(2.8) \mathrm{ng} / \mathrm{mL}$ after completion of six NET treatments, which is consistent with the findings of Regenold et al's study. ${ }^{19}$ The lack of a significant increase in serum BDNF levels following treatment with a course of NET should also be compared to findings reported on changes in serum BDNF levels with a course of ECT. Numerous studies have examined the effect of ECT on serum BDNF levels in patients with MDD, but with inconsistent findings. ${ }^{18,34-36}$ For example, a recent study found that when compared to baseline, serum BDNF levels were significantly higher after the final ECT session. ${ }^{34}$ Another study found no significant change in serum BDNF levels after ECT treatment. ${ }^{35}$

This study found no significant association between changes in serum BDNF levels and changes in depression severity with a course of NET, supporting the findings of Regenold et al's study. ${ }^{19}$ Similar to antidepressant therapy, BDNF appears to be a treatment biomarker for ECT outcome ${ }^{37}$ However, the findings on the potential association between serum BDNF levels and ECT outcome are mixed. ${ }^{34,38-40}$ For example, Kranaster et al reported that serum BDNF levels after a course of ECT were positively correlated with the Seizure Quality Index scores for response and remission in older patients with MDD. ${ }^{40}$ However, two recent studies found no significant association between serum BDNF levels and the antidepressant effects of ECT. ${ }^{36,39}$

Several methodological limitations should be noted. First, this was a single-arm, open-label study. Thus, these findings were susceptible to both subject and investigator bias. Second, the sample size of this study was relatively small, which can partly account for the negative findings. Third, bilateral NET was used in all patients with TRD, limiting the generalizability of these findings. Fourth, all subjects who continued to take the 
treatment with psychotropic medications may exert some effect on serum BDNF levels. Participants in this study had generalizability to "real-world" patients since most of them wised to continue receiving psychotropic medications for management of depressive symptoms, although these drugs had failed to lead to an antidepressant response. Fifth, blood samples were only collected at baseline and at the end of the course of NET for the depression cohort in this study. However, changes in serum BDNF levels after each session were not examined. Sixth, cortical BDNF levels were not directly collected in the current study, while BDNF can cross the blood-brain barrier and serum BDNF levels can potential reflect cortical levels of BDNF. ${ }^{41,42}$ Finally, only serum BDNF levels were analyzed to predict ECT outcome in this study, but optimal biomarker assessments could incorporate multiple modes of data acquisition, including neuroimaging ${ }^{43}$ and quantitative electroencephalography. ${ }^{44}$

\section{Conclusion}

Serum BDNF levels appear to have no clinical utility in the prediction of the antidepressant effects of NET in patients with TRD. Future studies of higher quality and with larger sample sizes are needed to confirm these findings and examine the effects of different parameter of NET and the potential influence on other molecular mediators involved in depression.

\section{Funding}

This study was funded by the Science and Technology Planning Project of Guangdong Province (B2016109), the Science and Technology Plan Project of Guangdong Province (2019B030316001), and Guangzhou Clinical Characteristic Technology Project (67).

\section{Disclosure}

The authors report no conflicts of interest in this work.

\section{References}

1. Friedrich MJ. Depression is the leading cause of disability around the world. JAMA. 2017;317(15):1517. doi:10.1001/jama.2017.5254

2. Duman RS, Monteggia LM. A neurotrophic model for stress-related mood disorders. Biol Psychiatry. 2006;59(12):1116-1127. doi:10.10 16/j.biopsych.2006.02.013

3. Notaras M, van den Buuse M. Neurobiology of BDNF in fear memory, sensitivity to stress, and stress-related disorders. Mol Psychiatry. 2020;1-24.

4. Molendijk ML, Spinhoven P, Polak M, Bus BA, Penninx BW, Elzinga BM. Serum BDNF concentrations as peripheral manifestations of depression: evidence from a systematic review and meta-analyses on 179 associations (N=9484). Mol Psychiatry. 2014;19(7):791-800. doi:10.1038/mp.2013.105
5. Kowianski P, Lietzau G, Czuba E, Waskow M, Steliga A, Morys J. BDNF: a key factor with multipotent impact on brain signaling and synaptic plasticity. Cell Mol Neurobiol. 2018;38(3):579-593. doi:10.1007/s10571-017-0510-4

6. Smith MA, Makino S, Kvetnansky R, Post RM. Stress and glucocorticoids affect the expression of brain-derived neurotrophic factor and neurotrophin-3 mRNAs in the hippocampus. J Neurosci. 1995;15 (3):1768-1777. doi:10.1523/JNEUROSCI.15-03-01768.1995

7. Nibuya M, Morinobu S, Duman RS. Regulation of BDNF and trkB mRNA in rat brain by chronic electroconvulsive seizure and antidepressant drug treatments. J Neurosci. 1995;15(11):7539-7547. doi:10.1523/JNEUROSCI.15-11-07539.1995

8. Mizui $\mathrm{T}$, Hattori $\mathrm{K}$, Ishiwata $\mathrm{S}$, et al. Cerebrospinal fluid BDNF pro-peptide levels in major depressive disorder and schizophrenia. J Psychiatr Res. 2019;113:190-198. doi:10.1016/j.jpsychires.2019.03. 024

9. Chu CL, Liang CK, Chou MY, et al. Decreased plasma brain-derived neurotrophic factor levels in institutionalized elderly with depressive disorder. J Am Med Dir Assoc. 2012;13(5):434-437. doi:10.1016/j. jamda.2011.08.006

10. Polyakova M, Stuke K, Schuemberg K, Mueller K, Schoenknecht P, Schroeter ML. BDNF as a biomarker for successful treatment of mood disorders: a systematic \& quantitative meta-analysis. J Affect Disord. 2015;174:432-440. doi:10.1016/j.jad.2014.11.044

11. Lee BH, Kim YK. Reduced platelet BDNF level in patients with major depression. Prog Neuropsychopharmacol Biol Psychiatry. 2009;33(5):849-853. doi:10.1016/j.pnpbp.2009.04.002

12. Tripp A, Oh H, Guilloux JP, Martinowich K, Lewis DA, Sibille E. Brain-derived neurotrophic factor signaling and subgenual anterior cingulate cortex dysfunction in major depressive disorder. Am J Psychiatry. 2012;169(11):1194-1202. doi:10.1176/appi.ajp.2012.12020248

13. Brunoni AR, Lopes M, Fregni F. A systematic review and meta-analysis of clinical studies on major depression and BDNF levels: implications for the role of neuroplasticity in depression. Int J Neuropsychopharmacol. 2008;11(8):1169-1180. doi:10.1017/ S1461145708009309

14. Kurita M, Nishino S, Kato M, Numata Y, Sato T. Plasma brain-derived neurotrophic factor levels predict the clinical outcome of depression treatment in a naturalistic study. PLoS One. 2012;7(6): e39212. doi:10.1371/journal.pone.0039212

15. Groves JO. Is it time to reassess the BDNF hypothesis of depression? Mol Psychiatry. 2007;12(12):1079-1088. doi:10.1038/sj.mp.4002075

16. Dong M, Zhu XM, Zheng W, et al. Electroconvulsive therapy for older adult patients with major depressive disorder: a systematic review of randomized controlled trials. Psychogeriatrics. 2018;18 (6):468-475. doi:10.1111/psyg.12359

17. Wang G, Zheng W, Li XB, et al. ECT augmentation of clozapine for clozapine-resistant schizophrenia: a meta-analysis of randomized controlled trials. J Psychiatr Res. 2018;105:23-32. doi:10.1016/j. jpsychires.2018.08.002

18. Huang $\mathrm{XB}$, Huang $\mathrm{X}, \mathrm{He} \mathrm{HB}$, et al. BDNF and the antidepressant effects of ketamine and propofol in electroconvulsive therapy: a preliminary study. Neuropsychiatr Dis Treat. 2020;16:901-908. doi:10.2147/NDT.S248190

19. Regenold WT, Noorani RJ, Piez D, Patel P. Nonconvulsive electrotherapy for treatment resistant unipolar and bipolar major depressive disorder: a proof-of-concept trial. Brain Stimul. 2015;8(5):855-861. doi:10.1016/j.brs.2015.06.011

20. APA. American Psychiatric Association: Structured Clinical Interview for DSM-IV. Vol. 36. Washington, DC: American Psychiatric Press; 1994.

21. Hamilton M. A rating scale for depression. J Neurol Neurosurg Psychiatry. 1960;23:56-62. doi:10.1136/jnnp.23.1.56

22. Zheng W, Zhou YL, Liu WJ, et al. Investigation of medical effect of multiple ketamine infusions on patients with major depressive disorder. J Psychopharmacol. 2019;33(4):494-501. doi:10.1177/ 0269881119827811 
23. Lin $\mathrm{CH}$, Chen MC, Yang WC, Lane HY. Early improvement predicts outcome of major depressive patients treated with electroconvulsive therapy. Eur Neuropsychopharmacol. 2016;26(2):225-233. doi:10. 1016/j.euroneuro.2015.12.019

24. Heijnen WT, Birkenhager TK, Wierdsma AI, van den Broek WW. Antidepressant pharmacotherapy failure and response to subsequent electroconvulsive therapy: a meta-analysis. J Clin Psychopharmacol. 2010;30(5):616-619. doi:10.1097/JCP.0b013e3181ee0f5f

25. Sackeim HA, Prudic J, Devanand DP, et al. A prospective, randomized, double-blind comparison of bilateral and right unilateral electroconvulsive therapy at different stimulus intensities. Arch Gen Psychiatry. 2000;57(5):425-434. doi:10.1001/archpsyc.57.5.425

26. Mulder RT, Joyce PR, Frampton C. Relationships among measures of treatment outcome in depressed patients. J Affect Disord. 2003;76 (1-3):127-135. doi:10.1016/S0165-0327(02)00080-0

27. Ke X, Ding Y, Xu K, et al. Serum brain-derived neurotrophic factor and nerve growth factor decreased in chronic ketamine abusers. Drug Alcohol Depend. 2014;142:290-294. doi:10.1016/j.drugalcdep. 2014.06.043

28. Bocchio-Chiavetto L, Bagnardi V, Zanardini R, et al. Serum and plasma BDNF levels in major depression: a replication study and meta-analyses. World J Biol Psychiatry. 2010;11(6):763-773. doi:10.3109/15622971003611319

29. Huang X, Huang X, Zhou Y, et al. Association of serum BDNF levels with psychotic symptom in chronic patients with treatment-resistant depression in a Chinese Han population. Psychiatry Res. 2017;257:279-283. doi:10.1016/j.psychres.2017.07.076

30. Chiou YJ, Huang TL. Serum brain-derived neurotrophic factors in taiwanese patients with drug-naive first-episode major depressive disorder: effects of antidepressants. Int $J$ Neuropsychopharmacol. 2017;20(3):213-218. doi:10.1093/ijnp/pyw096

31. Kishi T, Yoshimura R, Ikuta T, Iwata N. Brain-derived neurotrophic factor and major depressive disorder: evidence from meta-analyses. Front Psychiatry. 2018;8:308. doi:10.3389/fpsyt.2017.00308

32. Sen S, Duman R, Sanacora G. Serum brain-derived neurotrophic factor, depression, and antidepressant medications: meta-analyses and implications. Biol Psychiatry. 2008;64(6):527-532. doi:10.1016/ j.biopsych.2008.05.005

33. Lee BH, Kim H, Park SH, Kim YK. Decreased plasma BDNF level in depressive patients. J Affect Disord. 2007;101(1-3):239-244. doi:10.1016/j.jad.2006.11.005

34. Vanicek T, Kranz GS, Vyssoki B, et al. Acute and subsequent continuation electroconvulsive therapy elevates serum BDNF levels in patients with major depression. Brain Stimul. 2019;12(4):1041-1050. doi:10.1016/j.brs.2019.02.015
35. Fernandes B, Gama CS, Massuda R, et al. Serum brain-derived neurotrophic factor (BDNF) is not associated with response to electroconvulsive therapy (ECT): a pilot study in drug resistant depressed patients. Neurosci Lett. 2009;453(3):195-198. doi:10.1016/j.neulet. 2009.02.032

36. Rocha RB, Dondossola ER, Grande AJ, et al. Increased BDNF levels after electroconvulsive therapy in patients with major depressive disorder: a meta-analysis study. J Psychiatr Res. 2016;83:47-53. doi:10.1016/j.jpsychires.2016.08.004

37. van Zutphen EM, Rhebergen D, van Exel E, et al. Brain-derived neurotrophic factor as a possible predictor of electroconvulsive therapy outcome. Transl Psychiatry. 2019;9(1):155. doi:10.1038/s41398019-0491-9

38. van Diermen L, van den Ameele S, Kamperman AM, et al. Prediction of electroconvulsive therapy response and remission in major depression: meta-analysis. $B r J$ Psychiatry. 2018;212(2):71-80. doi:10. 1192/bjp.2017.28

39. Maffioletti E, Gennarelli M, Gainelli G, Bocchio-Chiavetto L, Bortolomasi M, Minelli A. BDNF genotype and baseline serum levels in relation to electroconvulsive therapy effectiveness in treatment-resistant depressed patients. $J$ ECT. 2019;35(3):189-194. doi:10.1097/YCT.0000000000000583

40. Kranaster L, Hellweg R, Sartorius A. Association between the novel seizure quality index for the outcome prediction in electroconvulsive therapy and brain-derived neurotrophic factor serum levels. Neurosci Lett. 2019;704:164-168. doi:10.1016/j.neulet.2019.04.023

41. Pillai A, Kale A, Joshi S, et al. Decreased BDNF levels in CSF of drug-naive first-episode psychotic subjects: correlation with plasma BDNF and psychopathology. Int J Neuropsychopharmacol. 2010;13 (4):535-539. doi:10.1017/S1461145709991015

42. Poduslo JF, Curran GL. Permeability at the blood-brain and blood-nerve barriers of the neurotrophic factors: NGF, CNTF, NT-3, BDNF. Brain Res Mol Brain Res. 1996;36(2):280-286. doi:10.1016/ 0169-328X(95)00250-V

43. Kambeitz J, Cabral C, Sacchet MD, et al. Detecting neuroimaging biomarkers for depression: a meta-analysis of multivariate pattern recognition studies. Biol Psychiatry. 2017;82(5):330-338. doi:10. 1016/j.biopsych.2016.10.028

44. Cook IA, Hunter AM, Gilmer WS, et al. Quantitative electroencephalogram biomarkers for predicting likelihood and speed of achieving sustained remission in major depression: a report from the biomarkers for rapid identification of treatment effectiveness in major depression (BRITE-MD) trial. J Clin Psychiatry. 2013;74 (1):51-56. doi:10.4088/JCP.10m06813
Neuropsychiatric Disease and Treatment

\section{Publish your work in this journal}

Neuropsychiatric Disease and Treatment is an international, peerreviewed journal of clinical therapeutics and pharmacology focusing on concise rapid reporting of clinical or pre-clinical studies on a range of neuropsychiatric and neurological disorders. This journal is indexed on PubMed Central, the 'PsycINFO' database and CAS, and is the official journal of The International Neuropsychiatric Association (INA). The manuscript management system is completely online and includes a very quick and fair peer-review system which is all easy to use. Visit http://www.dovepress.com/testimonials.php to read real quotes from published authors. 